\title{
Effect of chip load and spindle speed on cutting force of Hastelloy $X$
}

\author{
Nor Aznan Mohd Nor ${ }^{1 *}$, B.T.H.T Baharudin¹, J. A. Ghani² ${ }^{2}$ Z. Leman¹ and M.K.A. Ariffin ${ }^{1}$ \\ ${ }^{1}$ Department of Mechanical and Manufacturing Engineering, Faculty of Engineering, Universiti Putra Malaysia, 43400 Serdang, Malaysia. \\ ${ }^{2}$ Department of Mechanical and Materials Engineering, Faculty of Engineering and Built Environment, Universiti Kebangsaan Malaysia, \\ 43600 Bangi, Malaysia.
}

\begin{abstract}
Research on cutting force revealed that the cutting force decreases as cutting speed increases, which is in line with Salomon's Theory. However, the fundamental behaviour was never clearly explained because most studies had focused on increasing the cutting speed by increasing spindle speed without retaining the rate of chip load. On that note, the effect of increasing spindle speed while chip load is constant on the cutting force of Hastelloy $X$ is presented in this paper. Third Wave AdvantEdge software was applied and half-immersion up-milling simulations were conducted in dry condition. Result showed that the resultant force was primarily affected by the axial force, followed by normal force and feed force. Trend-lines indicated that the behaviour of cutting force components and resultant force was quadratic. Desirability Function Analysis (DFA) results revealed that the optimum combination of chip load and spindle speed led to lowest cutting force components and resultant force was at $0.013 \mathrm{~mm} /$ tooth and 24,100 RPM. Furthermore, the optimum cutting conditions that led to the lowest cutting force components and resultant force at chip loads of $0.016 \mathrm{~mm} /$ tooth and $0.019 \mathrm{~mm} /$ tooth was 24,100 RPM also. Therefore, increasing Material Removal Rate (MRR) while minimizing cutting force components and resultant force can be achieved by increasing the amount of chip load at spindle speed of 24,100 RPM.
\end{abstract}

ARTICLE HISTORY

Revised: $29^{\text {th }}$ Nov 2019

Accepted: $21^{\text {st }}$ Feb 2020

\section{KEYWORDS}

Chip load;

spindle speed;

cutting force;

Hastelloy $X$;

half-immersion up-milling

\section{INTRODUCTION}

The unique properties of Hastelloy $\mathrm{X}$ have already become the important advanced materials in petrochemical process equipment and gas turbine engines in the hot combustion zone sections. Some of their great mechanical properties include outstanding high temperature strength and oxidation resistance $[1,2]$. However, its great mechanical properties have caused difficulty in metal cutting and a high cutting force was generated in this advanced material machining. Additionally, when the high cutting force was generated, the tool life was decreased and reduced the surface quality of the machined material due to catastrophic vibration [3]. Almost a century ago, the cutting force research was developed at supersonic rate worldwide through a German patent number 523594 dated April 27, 1931. The patent was based on a theory by Dr. Carl J. Salomon, in that by increasing the cutting speed will decrease the cutting force. Based on this theory the idea of High Speed Machining (HSM) was generated [4, 5]. Furthermore, the great contribution of HSM can be seen by the initial investment documents as stated in [6] whereby the MRR increased fivefold, machining time and cost reduced to $70 \%$ and $25 \%-50 \%$, respectively, and there was an exponential increase in productivity. Nevertheless, the fundamental behaviour was not clearly explained because most studies had focused on increasing cutting speed by increasing spindle speed without retaining the rate of chip load. As cutting speed is tied to spindle speed, increasing spindle speed will increase cutting speed then causes the transition from Conventional Machining (CM) to HSM. On the other side, feed rate is decreased with respect to decreasing the chip load. Further, as reported in [7-9], cutting force is found to decrease with an increase in spindle speed, while as chip load decreases the cutting force will also decrease. Therefore, increasing spindle speed while decreasing chip load will significantly decrease the cutting force during metal cutting. However, a small chip load will result in a low feed rate and low MRR; consequently, it is contrary to the objective of HSM that promises an increase in MRR by increasing the cutting speed and feed rate. Therefore, this paper presents an understanding towards the cutting force behaviour of Hastelloy $\mathrm{X}$ when the spindle speed is increased. Meanwhile the chip load is constant in half-immersion up-milling operation. Besides, up-milling has been recognised as the preferred way to machine hardened surface since the cuts begin under the surface of the machined material.

\section{SIMULATION SET-UP}

Effects of chip load and spindle speed on the cutting force of Hastelloy X were identified by FEM simulation in Third Wave AdvantEdge software for all runs as shown in Table 1. Spindle speed was increased from 13,300 RPM to 37,600 RPM while chip load and depth of cut were held constant at $0.013 \mathrm{~mm} /$ tooth and $0.2 \mathrm{~mm}$. The same method was repeated by replacing the chip load of $0.013 \mathrm{~mm} /$ tooth to $0.016 \mathrm{~mm} /$ tooth and $0.019 \mathrm{~mm} /$ tooth. The workpiece material used was $90 \mathrm{~mm}$ x $40 \mathrm{~mm}$ x $10 \mathrm{~mm}$ Hastelloy X with original hardness of $92 \mathrm{HR}_{\mathrm{B}}$. Table 2 shows the chemical composition of Hastelloy X. 
Table 1. Variable parameters used in the simulation.

\begin{tabular}{cc}
\hline Parameter & Value \\
\hline Chip load (mm/tooth) & $0.013,0.016,0.019$ \\
Spindle speed (RPM) & 13,300 to 37,600 \\
Depth of cut (mm) & 0.2 \\
\hline
\end{tabular}

Table 2. Chemical composition of Hastelloy X (wt\%).

\begin{tabular}{ccccccccc}
\hline $\mathrm{Ni}$ & $\mathrm{Cr}$ & $\mathrm{Fe}$ & $\mathrm{Mo}$ & $\mathrm{W}$ & $\mathrm{Mn}$ & $\mathrm{Co}$ & $\mathrm{Si}$ & $\mathrm{P}, \mathrm{S}$ \\
\hline 47.2 & 22.8 & 18.5 & 8.2 & 0.71 & 0.49 & 0.73 & 0.24 & $<0.008$ \\
\hline
\end{tabular}

The end-milling was performed as half-immersion up-milling under dry condition by using KYS40 solid ceramic endmill with diameter of $6 \mathrm{~mm}$ with 4 flutes from Kennametal. Furthermore, the STL file of the end-mill was provided by the end-mill manufacturer then imported into Third Wave Systems AdvantEdge software for the purpose of performing the simulation tests. Furthermore, the simulation results in the three directions or cutting force components, namely feed force $(\mathrm{Fx})$, normal force $(\mathrm{Fy})$ and axial force $(\mathrm{Fz})$ were recorded. Finally, the resultant force (Fr) was calculated using Equation. (1).

$$
F_{r}=\sqrt{F_{x^{2}}+F_{y^{2}}+F_{z^{2}}}
$$

The values of cutting force components and resultant force were plotted on X-Y plot, and then it was analysed in terms of percentage contribution of each cutting force component to resultant force, as well as the behaviour of cutting force components and resultant force using trend-line. Next, DFA through Minitab 19 software was applied for determining the optimum spindle speed at chip loads of $0.013 \mathrm{~mm} /$ tooth, $0.016 \mathrm{~mm} /$ tooth and $0.019 \mathrm{~mm} /$ tooth that lead to the lowest cutting force components and resultant force. In addition, the highest value of composite desirability (D) gives the optimum cutting conditions.

\section{RESULTS AND DISCUSSION}

As presented in Figure 1, the cutting force of the half-immersion up-milling operation in dry condition was estimated through a simulation by Third Wave AdvantEdge software at different chip load and spindle speed levels, while the depth of cut were kept constant. By referring to the simulation results in Figure 2, Figure 3, Figure 4, and Figure 5, the contribution of axial force during cutting operation accounted for about $60 \%$ of resultant force. In addition, normal force and feed force contributed approximately $25 \%$ and $15 \%$, respectively, in resultant force. Even though the nature was contrary to the study by Nalbant and Yildiz [10], Sultan and Okafor [11], and Zhang, Zhang and Li [12], it was in line with the study conducted by Ravi and Pradeep Kumar [13] who showed that axial force was the dominant factor which affected the resultant force, followed by normal force and feed force. Additionally, the percentage contribution of each cutting force components to resultant force for half-immersion up-milling Hastelloy X can be ordered from high to low as $\mathrm{Fz}>\mathrm{Fy}>\mathrm{Fx}$.

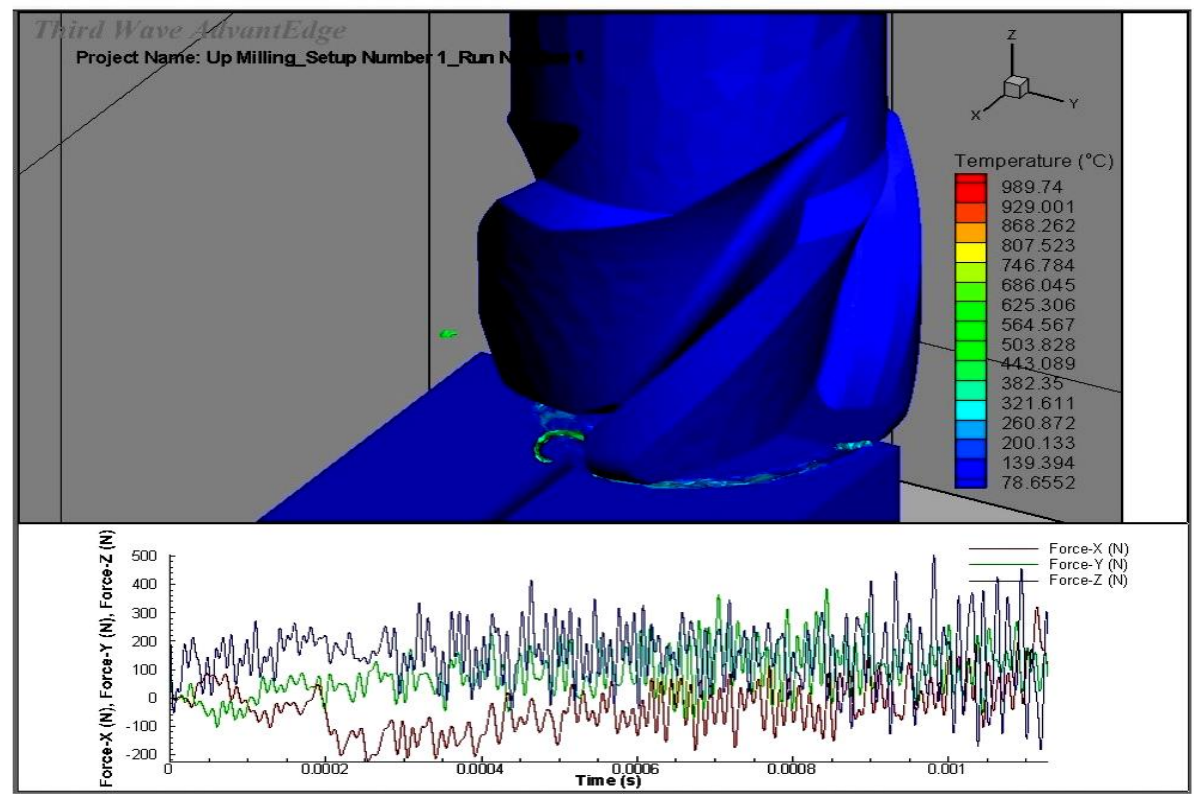

Figure 1. Cutting force components in half-immersion up-milling. 
Besides the difference in contribution on the resultant force, at chip loads of $0.013 \mathrm{~mm} / \mathrm{tooth}, 0.016 \mathrm{~mm} / \mathrm{tooth}$, and $0.019 \mathrm{~mm} /$ tooth, Figure 2 shows that the resultant force decreased when spindle speed is increased at constant chip load, then increased after reaching a specific spindle speed, even when spindle speed increased further. This phenomenon was similar with the HSM theory as indicated by Liu, Chu, Zeng, $\mathrm{He}, \mathrm{Wu}, \mathrm{Wu}$ and $\mathrm{Wu}$ [14], in which the cutting force decreases as the cutting speed increases after the cutting speed exceeds the death zone. Meanwhile, for the next region behaviour which is the resultant force increases as spindle speed increases can be related with ductile regime or brittle regime alone [15]. Wang, $\mathrm{Liu}, \mathrm{Su}$, Song and $\mathrm{Ai}$ [15] stated that during the transition period from ductile regime to brittle regime, cutting force decreases as cutting speed increases which is similar to the HSM theory mentioned by Liu et al. [14]. Meanwhile, during ductile regime or brittle regime alone, the cutting force increases with increasing cutting speed [15] then it is the answer for the next region behaviour.

As the behaviour of the resultant force firstly decreases and then increases when the spindle speed is kept increased, it can be claimed that the behaviour of cutting force is quadratic when spindle speed is increased instead of inverse linearly to the increased spindle speed, as previously reported by [16]. Cutting force components also illustrate the similar behaviour as can be seen in Figure 3 to Figure 5. However, the axial force at chip load of $0.019 \mathrm{~mm} /$ tooth has inverse Ushape behaviour when the spindle speed increases from 13,300 RPM to 37,600 RPM. Due to this, the behaviour of resultant force of the U-shape at chip loads of $0.019 \mathrm{~mm} /$ tooth is not too curvy as compared with the U-shape behaviour of resultant force at chip loads of $0.013 \mathrm{~mm} /$ tooth and $0.016 \mathrm{~mm} /$ tooth.

\section{Resultant Force against Spindle Speed}

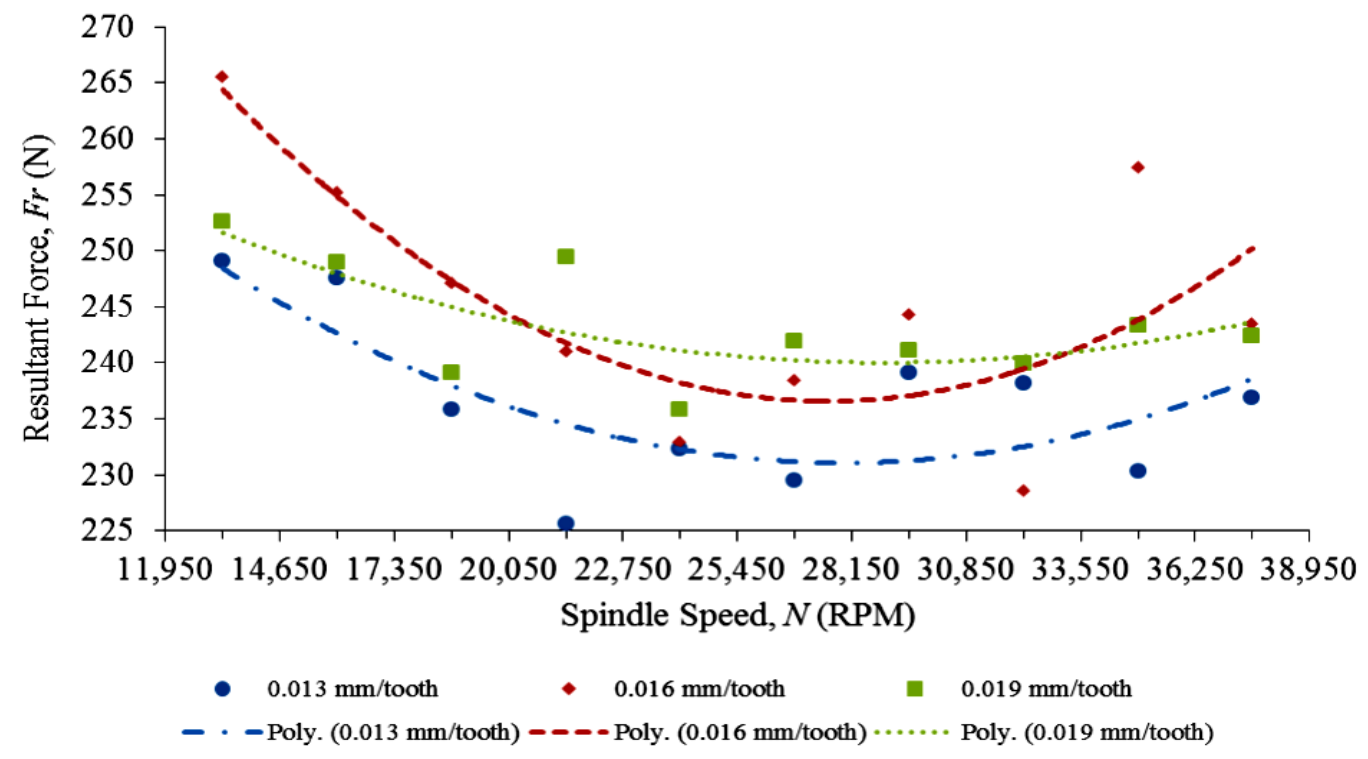

Figure 2. Resultant force against spindle speed.

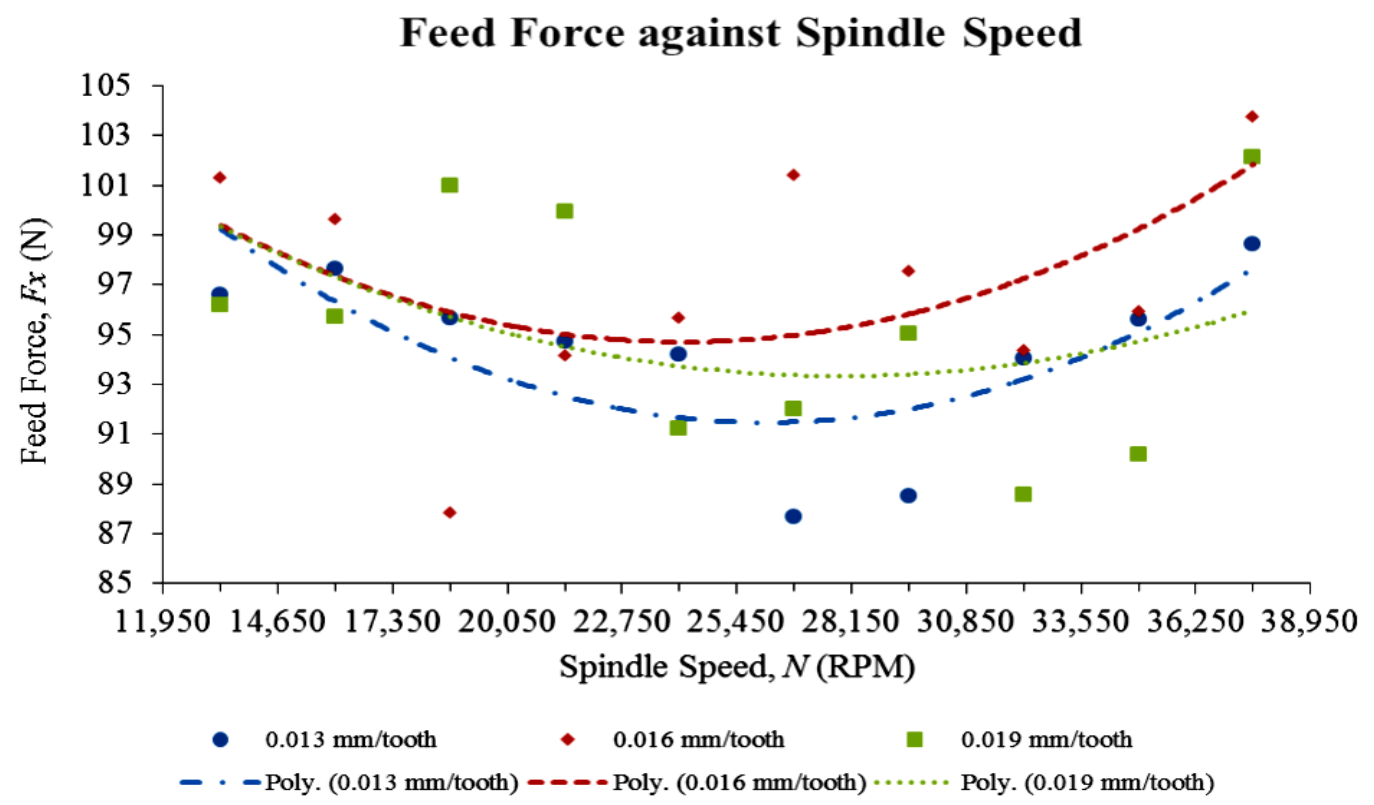

Figure 3. Feed force against spindle speed. 


\section{Normal Force against Spindle Speed}

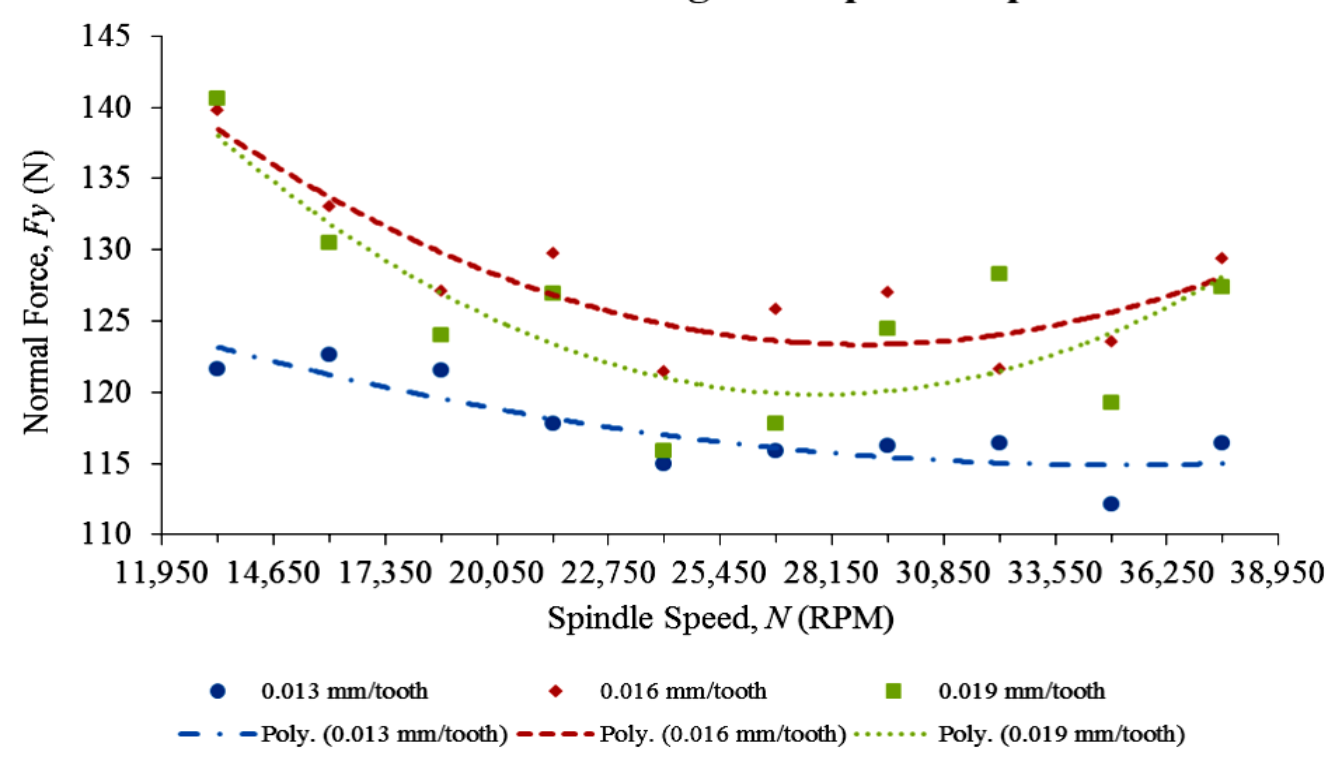

Figure 4. Normal force against spindle speed.

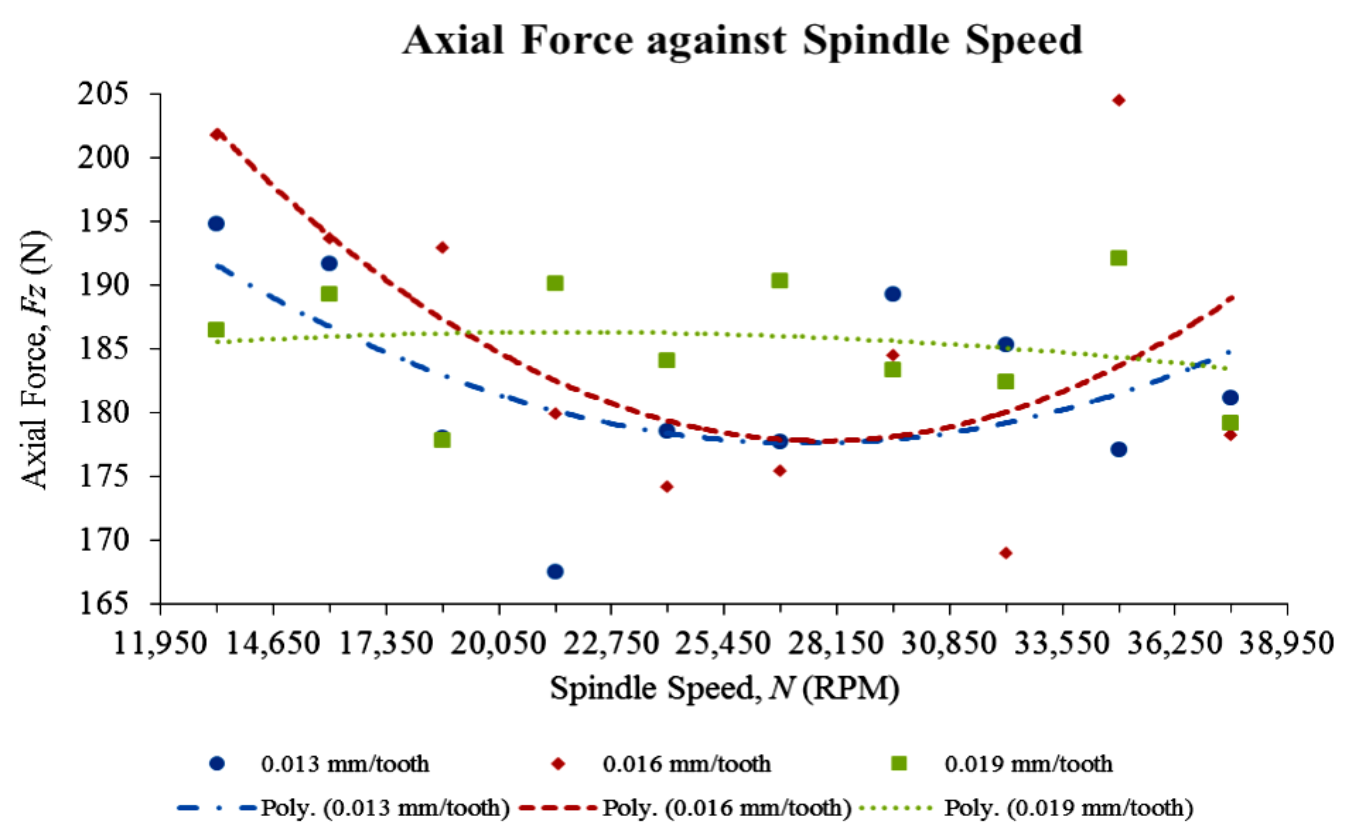

Figure 5. Axial force against spindle speed.

As the findings revealed that the behaviour of cutting force components and resultant force were quadratic, which indirectly increased the spindle speed to the maximum spindle speed at 37,600 RPM for the purpose to reduce cutting fore components and resultant force during half-immersion up-milling with Hastelloy $\mathrm{X}$ becoming unnecessary. This was also supported by the DFA results. A selective DFA results (Optimisation plot) is shown in Figure 6. The results revealed that the optimum combination of chip load and spindle speed leading to the lowest cutting force components and resultant force was at $0.013 \mathrm{~mm} /$ tooth and 24,100 RPM, as this combination has the highest D value. Furthermore, Table 3 shows the summarised data from the whole DFA results and it was noticed that the optimum spindle speed which led to the lowest cutting force components and resultant force at chip loads of $0.016 \mathrm{~mm} /$ tooth and $0.019 \mathrm{~mm} /$ tooth is at 24,100 RPM. 


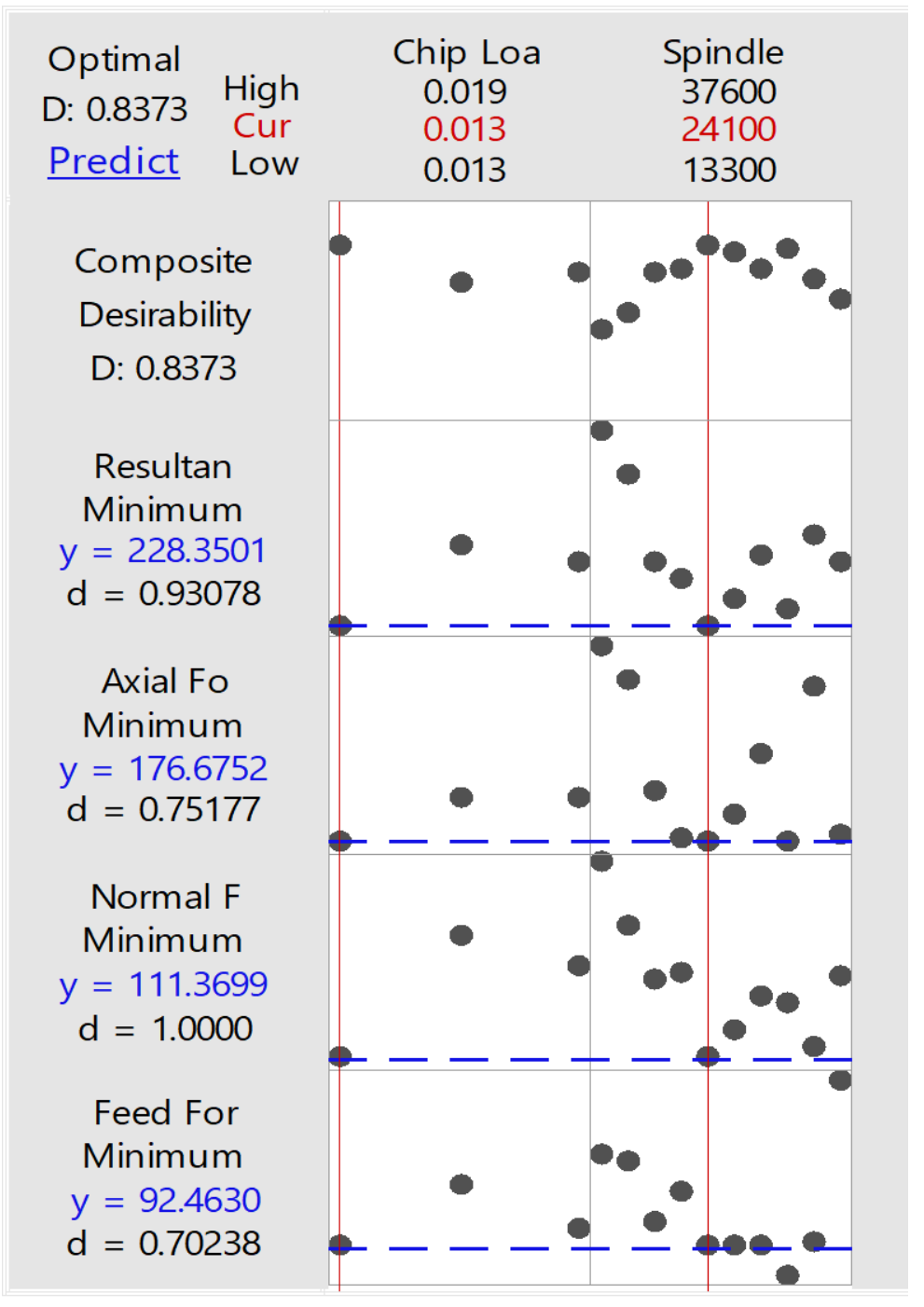

Figure 6. Optimisation plot for half-immersion up-milling.

Table 3. Overall composite desirability with individual desirability for half-immersion up-milling.

\begin{tabular}{|c|c|c|c|c|c|c|}
\hline \multirow{2}{*}{$\begin{array}{c}\text { Spindle } \\
\text { Speed } \\
\text { (RPM) }\end{array}$} & \multirow{2}{*}{$\begin{array}{c}\text { Chip Load } \\
\text { (mm/tooth) }\end{array}$} & $\begin{array}{c}\text { Feed } \\
\text { Force }\end{array}$ & $\begin{array}{c}\text { Normal } \\
\text { Force }\end{array}$ & $\begin{array}{c}\text { Axial } \\
\text { Force }\end{array}$ & $\begin{array}{c}\text { Resultant } \\
\text { Force }\end{array}$ & $\begin{array}{c}\text { Composite } \\
\text { Desirability }\end{array}$ \\
\cline { 3 - 6 } 13300 & 0.013 & 0.4333 & 0.4446 & 0.3358 & 0.3790 & 0.3957 \\
\hline 16000 & 0.013 & 0.4555 & 0.6308 & 0.4109 & 0.5073 & 0.4947 \\
\hline 18700 & 0.013 & 0.6326 & 0.7879 & 0.6440 & 0.7553 & 0.7017 \\
\hline 21400 & 0.013 & 0.5427 & 0.7664 & 0.7453 & 0.8060 & 0.7070 \\
\hline 24100 & 0.013 & 0.7024 & 1.0000 & 0.7518 & 0.9308 & 0.8373 \\
\hline 26800 & 0.013 & 0.7029 & 0.9415 & 0.6920 & 0.8562 & 0.7913 \\
\hline 29500 & 0.013 & 0.7022 & 0.8448 & 0.5691 & 0.7351 & 0.7058 \\
\hline 32200 & 0.013 & 0.7877 & 0.8609 & 0.7527 & 0.8836 & 0.8195 \\
\hline 34900 & 0.013 & 0.6891 & 0.9951 & 0.4198 & 0.6790 & 0.6649 \\
\hline 37600 & 0.013 & 0.2160 & 0.7818 & 0.7358 & 0.7504 & 0.5526 \\
\hline 13300 & 0.016 & 0.2580 & 0.0836 & 0.2462 & 0.1547 & 0.1693 \\
\hline 16000 & 0.016 & 0.2802 & 0.2698 & 0.3214 & 0.2830 & 0.2880 \\
\hline 18700 & 0.016 & 0.4573 & 0.4269 & 0.5545 & 0.5310 & 0.4896 \\
\hline
\end{tabular}




\begin{tabular}{|l|l|l|l|l|l|l|}
\hline 21400 & 0.016 & 0.3675 & 0.4054 & 0.6558 & 0.5817 & 0.4882 \\
\hline 24100 & 0.016 & 0.5271 & 0.6640 & 0.6622 & 0.7065 & 0.6361 \\
\hline 26800 & 0.016 & 0.5276 & 0.5805 & 0.6025 & 0.6318 & 0.5843 \\
\hline 29500 & 0.016 & 0.5269 & 0.4838 & 0.4796 & 0.5108 & 0.4999 \\
\hline 32200 & 0.016 & 0.6124 & 0.4999 & 0.6632 & 0.6593 & 0.6049 \\
\hline 34900 & 0.016 & 0.5139 & 0.6341 & 0.3302 & 0.4547 & 0.4703 \\
\hline 37600 & 0.016 & 0.0408 & 0.4208 & 0.6463 & 0.5261 & 0.2763 \\
\hline 13300 & 0.019 & 0.3795 & 0.1656 & 0.2439 & 0.2027 & 0.2361 \\
\hline 16000 & 0.019 & 0.4017 & 0.3518 & 0.3190 & 0.3310 & 0.3495 \\
\hline 18700 & 0.019 & 0.5789 & 0.5089 & 0.5521 & 0.5789 & 0.5539 \\
\hline 21400 & 0.019 & 0.4890 & 0.4874 & 0.6534 & 0.6297 & 0.5596 \\
\hline 24100 & 0.019 & 0.6486 & 0.7460 & 0.6599 & 0.7544 & 0.7006 \\
\hline 26800 & 0.019 & 0.6492 & 0.6625 & 0.6001 & 0.6798 & 0.6472 \\
\hline 29500 & 0.019 & 0.6484 & 0.5658 & 0.4772 & 0.5588 & 0.5592 \\
\hline 32200 & 0.019 & 0.7339 & 0.5819 & 0.6608 & 0.7073 & 0.6684 \\
\hline 34900 & 0.019 & 0.6354 & 0.7161 & 0.3278 & 0.5027 & 0.5233 \\
\hline 37600 & 0.019 & 0.1623 & 0.5028 & 0.6439 & 0.5741 & 0.4167 \\
\hline
\end{tabular}

Since the minimum cutting force components and resultant force was at spindle speed of 24,100 RPM for all level of chip loads, it can be proposed that the combination of chip load and spindle speed at $0.013 \mathrm{~mm} /$ tooth and $24,100 \mathrm{RPM}$ would be perfect for the manufacturing industry to achieve the lowest cutting force during half-immersion up-milling Hastelloy X. Meanwhile, performing half-immersion up-milling Hastelloy X at chip load of $0.019 \mathrm{~mm} /$ tooth and spindle speed of 24,100 RPM can ensure that the cutting force components and resultant force were still at low level while increasing MRR. Meanwhile, half-immersion up-milling Hastelloy X at chip load of $0.016 \mathrm{~mm} /$ tooth and spindle speed of 24,100 RPM gave the equilibrium in terms of the level of cutting force components, resultant force and MRR.

\section{CONCLUSION}

Salomon's Theory is driving a rising cutting force research in HSM for decreasing the cutting force by increasing the cutting speed. Even though these findings gave a positive impact, the fundamental behaviour was not clearly explained because most cutting force research had focused on the approach of increasing the cutting speed by increasing spindle speed without retaining the rate of chip load. In this respect, the half-immersion up-milling simulations were performed to determine the effect of increasing spindle speed while chip load was constant on the cutting force of Hastelloy $\mathrm{X}$ in dry conditions, and the result showed that axial force has a major contribution on resultant force, followed by normal force and feed force. Furthermore, trend lines indicated that the behaviour of cutting force components and resultant force was quadratic instead of inverse linearly to the increased spindle speed as indicated in the most cutting force research. Thus, increasing the spindle speed to the maximum spindle speed during half-immersion up-milling Hastelloy $\mathrm{X}$ in order to achieve low cutting force has become unnecessary, due to the optimum spindle speed at all levels of chip load that was at the intermediate range of spindle speed. More specifically, DFA results revealed that the optimum combination of chip load and spindle speed that led to the lowest cutting force components and resultant force was at $0.013 \mathrm{~mm} / \mathrm{tooth}$ and 24,100 RPM. In addition, the optimum spindle speed that led to the lowest cutting force components and resultant force at chip load $0.016 \mathrm{~mm} /$ tooth and $0.019 \mathrm{~mm} /$ tooth at 24,100 RPM. Since the optimum spindle speed at all level of chip load was at 24,100 RPM, it will enable manufacturing industry to increase MRR by increasing the amount of chip load at spindle speed of 24,100 RPM as it can ensure that the cutting force components and resultant force would be still at the low level instead of increasing spindle speed to the maximum level. Lastly, an interesting future study might involve the verification of the effect on surface integrity in HSM of Hastelloy X since the minimum cutting force does not necessarily produce a better surface integrity.

\section{ACKNOWLEDGEMENTS}

The authors would like to acknowledge the financial support from the Universiti Putra Malaysia under Research Grant no. GP-IPS/2017/9539900 as well as Mr. Mohd Nor Bin Puteh, Mdm. Hatijah Binti Kassim, Mdm. Dyg. Siti Quraisyah Bt. Abg. Adenan and Mr. Nor Iman Ziqri Bin Nor Aznan for encouragement. 


\section{REFERENCES}

[1] Wang X, Dallemagne A, Hou Y, Yang S. Effect of thermomechanical processing on grain boundary character distribution of Hastelloy X alloy. Materials Science and Engineering: A. 2016; 669: 95-102.

[2] Esmaeilzadeh M, Qods F, Arabi H, Sadeghi B. An investigation on crack growth rate of fatigue and induction heating thermomechanical fatigue (TMF) in Hastelloy X superalloy via LEFM, EPFM and integration models. International Journal of Fatigue. 2017; 97: 135-149.

[3] Shokrani A, Dhokia V, Newman S. Environmentally conscious machining of difficult-to-machine materials with regard to cutting fluids. International Journal of Machine Tools and Manufacture. 2012; 57: 83-101.

[4] Brinksmeier E, Preuss W, Riemer O, Rentsch R. Cutting forces, tool wear and surface finish in high speed diamond machining. Precision Engineering. 2017; 49: 293-304.

[5] Longbottom J, Lanham J. A review of research related to Salomon's hypothesis on cutting speeds and temperatures. International Journal of Machine Tools and Manufacture. 2006; 46(14): 1740-1747.

[6] Grzesik W. Advanced machining processes of metallic materials. Theory, modelling and applications. Elsevier: Elsevier Amsterdam; 2017.

[7] Dikshit MK, Puri AB, Maity A. Experimental Study of Cutting Forces in Ball End Milling of Al2014-T6 Using Response Surface Methodology. Procedia Materials Science. 2104; 6: 612-622.

[8] Tsai M, Chang S, Hung J, Wang C. Investigation of milling cutting forces and cutting coefficient for aluminum 6060-T6. Computers \& Electrical Engineering. 2016; 51: 320-330.

[9] San-Juan M, Martín Ó, Tiedra MD, Santos F, López R, Cebrián J. Study of cutting forces and temperatures in milling of AISI 316L. Procedia Engineering. 2015; 132: 500-506.

[10] Nalbant M, Yildiz Y. Effect of cryogenic cooling in milling process of AISI 304 stainless steel. Transactions of Nonferrous Metals Society of China. 2011; 21(1): 72-79.

[11] Sultan AA, Okafor AC. Effects of geometric parameters of wavy-edge bull-nose helical end-mill on cutting force prediction in end-milling of Inconel 718 under MQL cooling strategy. Journal of Manufacturing Processes. 2016; 23: 102-114.

[12] Zhang Q, Zhang S, Li J. Three dimensional finite element simulation of cutting forces and cutting temperature in hard milling of AISI H13 Steel. Procedia Manufacturing. 2017; 10: 37-47.

[13] Ravi S, Pradeep Kumar M. Experimental investigations on cryogenic cooling by liquid nitrogen in the end milling of hardened steel. Cryogenics. 2011; 51(9): 509-515.

[14] Liu W, Chu Q, Zeng J, He R, Wu H, Wu Z, Wu S. PVD-CrAlN and TiAlN coated Si3N4 ceramic cutting inserts-2. High speed face milling performance and wear mechanism study. Ceramics International. 2017; 43(12): 9488-9492.

[15] Wang B, Liu Z, Su G, Song Q, Ai X. Investigations of critical cutting speed and ductile-to-brittle transition mechanism for workpiece material in ultra-high speed machining. International Journal of Mechanical Sciences. 2015; 104: 44-59.

[16] Selvaraj D. Optimization of cutting force of duplex stainless steel in dry milling operation. Materials Today Proceedings. 2017; 4(10): 11141-11147. 